\title{
A TEORIA PRAGMÁTICA DA NORMA JURÍDICA E O IMPERATIVISMO: UMA ANÁLISE LUHMANNIANA
}

\section{Pythagoras Lopes de Carvalho Neto ${ }^{1}$}

\section{Resumo}

Este artigo compara, sob a perspectiva da teoria dos sistemas autor referenciais, a concepção de norma jurídica da pragmática jurídica formulada por Tercio Sampaio Ferraz Jr. e do imperativismo jurídico positivista. A comparação é feita em três níveis: o nível da sociedade, do direito e da teoria do direito. No primeiro, a pragmática jurídica compartilha, de forma mitigada, a visão imperativista da função do direito como orientação de condutas. No segundo nível, a pragmática segue o imperativismo ao analisar a norma jurídica sob o ponto de vista de sua criação, não de sua aplicação. Finalmente, no plano da teoria do direito, a pragmática jurídica avança em relação ao imperativismo por distinguir os aspectos sociais e temporais da normatividade, mas deixa de explorar essa distinção em razão das opções teóricas adotadas nos níveis anteriores.

Palavras-chave: norma jurídica - imperativismo - pragmática jurídica - positivismo jurídico - teoria dos sistemas

\section{INTRODUÇÃO}

Este artigo pretende analisar, sob a perspectiva da teoria dos sistemas luhmanniana, as relações e diferenças que podem ser apontadas entre, de um lado, a teoria pragmática da norma jurídica desenvolvida por Tercio Sampaio Ferraz Jr. e, de outro lado, o imperativismo, teoria da norma prevalecente no pensamento jurídico nos séculos XIX e XX. Apesar de a teoria pragmática não pretender filiar-se ao imperativismo, a comparação entre esses dois paradigmas teóricos parece, à primeira vista, ser uma abordagem interessante, já que permite por em destaque as inovações trazidas por uma das mais recentes tentativas de reformulação da teoria da norma.

Pode ser entendida como imperativista a teoria que vê na norma jurídica um comando emitido por uma autoridade que prescreve uma determinada conduta omissiva ou comissiva a alguém que lhe está subordinado. Essa concepção informou uma grande variedade de teorias formuladas no pensamento jurídico europeu especialmente a partir dos séculos XIX e XX. De modo geral, é possível afirmar que tais teorias procuravam superar a concepção jusnaturalista do Direito, vinculando-se ao positivismo - em suas várias formas de manifestação - na tentativa de compreender o papel da norma jurídica em vistas das profundas mudanças por que passava o Direito. Norberto Bobbio, ele próprio um imperativista, chega mesmo a afirmar que o

\footnotetext{
${ }^{1}$ Doutor em Teoria Geral e Filosofia do Direito pela Universidade de São Paulo. E-mail: plcarvalhont@hotmail.com
} vol.10, nº. 04, Rio de Janeiro, 2017.pp. 2257-2278 
imperativismo é, por excelência, a teoria da norma do positivismo jurídico (BOBBIO, 1995: 132, 237-8).

A teoria pragmática da norma jurídica, por sua vez, surge, na segunda metade do século XX, como uma tentativa de superar as críticas dirigidas ao que se considerava um excessivo formalismo do positivismo no trato das questões jurídicas, entre elas o problema da norma. Com efeito, como será mais bem explorado na Seção III deste artigo, ao longo da segunda metade do século XIX e da primeira metade do século XX, a concepção original da norma como comando vai se esmaecendo e assumindo um caráter analógico ou, no dizer de Kelsen, metafórico. Essa insatisfação com o formalismo positivista e imperativista leva a tentativas de buscar assentar a teoria do Direito (e, portanto, da norma jurídica) em fundamentos mais vinculados ao contexto em que o fenômeno jurídico se desenrola, sem, contudo, por de lado as conquistas teóricas positivistas. Uma dessas tentativas é justamente a teoria pragmática, que pretende destacar a importância da situação comportamental e comunicativa dos agentes na vida do Direito. Nesses termos, uma comparação entre o modelo teórico imperativista e aquele elaborado pela pragmática jurídica parece uma forma promissora de medir o quanto se conseguiu avançar nesse propósito.

A comparação proposta partirá da premissa de que tanto o imperativismo quanto a pragmática são formas de descrever, de modo operacional para o sistema jurídico, as modificações estruturais decorrentes da positivação do Direito no século XIX. Desse modo, este artigo não pretende adotar a perspectiva de uma teoria geral do Direito, mas, em seu lugar, procurará seguir uma abordagem de caráter sociológico. Tendo em vista que a análise sociológica será aplicada não às efetivas operações do Direito, mas às descrições jurídicas de tais operações, parece correto designá-la como uma sociologia da teoria geral do Direito (CARVALHO NETO, 2007).

A fim de desenvolver a análise na perspectiva acima referida, será adotado um modelo teórico baseado na teoria dos sistemas de Niklas Luhmann. Esse modelo mostra-se especialmente atraente pelo fato de seu autor ter por preocupação teórica a formulação de uma teoria geral da sociedade, capaz de compreender todos os fenômenos sociais — inclusive aqueles relacionados ao Direito. Desse modo, como se poderá perceber na Seção II deste artigo, o referencial teórico proposto parece adequado para vincular, de um lado, as modificações na estrutura social que levaram à positivação do Direito e, de outro lado, a forma como a teoria jurídica reagiu a essas mudanças estruturais.

Nesses termos, o artigo inicia-se com a apresentação do modelo teórico utilizado para a análise tanto do imperativismo quanto da pragmática jurídica. Será a oportunidade de explicar os principais conceitos de teoria dos sistemas utilizados na análise subsequente, bem como sua articulação interna. Em seguida, será apresentado um breve resumo da evolução da teoria imperativista, destacando as vantagens e limitações que lhe podem ser atribuídas sob a perspectiva da teoria luhmanniana. Feito isso, a mesma análise será reproduzida com relação à teoria pragmática da norma jurídica, o que permitirá efetuar uma comparação entre essa teoria e o imperativismo. 
Ao final, serão apresentadas as conclusões deste estudo.

\section{MODELO TEÓRICO: EVOLUÇÃO SEMÂNTICA E A TEORIA DOS SISTEMAS}

Como já referido na seção introdutória, a teoria adotada para escorço teórico deste trabalho é a teoria dos sistemas de Niklas Luhmann. Essa teoria é formulada não a partir de identidades (como eram, por exemplo, as filosofias antigas, construídas em torno do problema do ser), mas, ao contrário, com base em diferenças. Em seu plano mais abstrato, as diferenças utilizadas pela teoria luhmanniana podem ser reconduzidas ao par sistema/ambiente, em que o sistema se caracteriza por sua recursividade, ou seja, pela capacidade de reutilizar a mesma diferença sistema/ambiente dentro de si, a fim de realizar suas operações. De acordo com essa teoria, a sociedade, de modo geral, e o Direito, de modo específico, devem ser entendidos como sistemas, os quais se reproduzem por meio das diferenças informação/ato de comunicação/entendimento, no caso da sociedade, e lícito/ilícito, no caso do sistema jurídico. É por meio da aplicação recursiva dessas diferenças que a sociedade e o Direito modificam-se a si próprios, em conformidade com suas próprias estruturas.

A hipótese que serve de premissa a este estudo é a afirmação de que a teoria da norma jurídica, na condição de observação do Direito realizada pelo próprio sistema jurídico, reflete as modificações estruturais por que passa o Direito e a sociedade. Essa afirmação decorre da aceitação de duas premissas: em primeiro lugar, o sistema jurídico, utilizando de forma recursiva sua diferença específica (em termos luhmannianos, seu código binário), qual seja, o par lícito/ilícito, é capaz de descrever a si próprio e a suas alterações estruturais; em segundo lugar, ainda que existam, no sistema jurídico, uma pluralidade de formas de auto-observação, o papel de descrição do sistema em seu nível mais geral e abstrato é exercido pela teoria do direito que, inclui a teoria da norma jurídica.

Sob o ponto de vista da teoria dos sistemas, a premissa teórica acima adotada pode ser articulada a partir da diferença entre estrutura social e semântica. De um lado, estruturas sociais são expectativas que direcionam a reprodução das comunicações, possibilitando a continuidade da existência de sistemas sociais. Se os sistemas sociais ${ }^{2}$ são a reprodução constante de comunicações, que são, para tais sistemas, seus elementos (também referidos como suas operações), as estruturas sociais são simplificações que direcionam o processo reprodutivo ao reduzir infinitas possibilidades a apenas duas hipóteses: confirmação da expectativa ou frustração da expectativa. Assim, por exemplo, a expectativa social de que, na sala de aula, os alunos devem prestar atenção à fala do professor

\footnotetext{
${ }^{2}$ Na teoria dos sistemas luhmanniana, o termo "sistemas sociais" refere-se, genericamente, a todos os sistemas que processam sentido por meio de comunicações (em oposição, por exemplo, a sistemas psíquicos, que processam sentido por meio de consciência). Esse termo, portanto, não deve ser confundido com outros termos que nele estão compreendidos, tais como "sociedade" (sistema social mais abrangente, que inclui todas as comunicações e, portanto, todos os demais sistemas sociais) e "sistemas parciais" ou "subsistemas" (sistemas sociais resultantes da diferenciação interna da sociedade, mediante a adoção de uma diferença específica, como, no caso do Direito, a diferença lícito/ilícito, já citada no corpo do texto, ou, no caso da Economia, a diferença ter/não-ter).
} 
permite que qualquer comportamento adotado por um aluno seja classificado pelo professor de acordo com a diferença atenção/desatenção, facilitando a escolha da reação adequada (no caso da atenção, uma avaliação positiva; no caso da desatenção, uma avaliação negativa e, possivelmente, uma advertência). Nesses termos, em um sistema composto por comunicações, as estruturas auxiliam a reprodução das operações ao indicar uma reação considerada adequada a qualquer comunicação que surja no caso concreto.

De outro lado, a semântica é um tipo específico de estrutura social que se distingue por estruturar as observações conduzidas pelo sistema, seja com relação a si mesmo, seja com relação a seu ambiente. Aparece, assim, como o patrimônio conceitual de um sistema social. É com base na semântica que o sistema é capaz de identificar relações entre um evento específico e eventos anteriores, facilitando, portanto, a compreensão e assimilação do novo evento. Fazem da parte da semântica do pensamento filosófico europeu tradicional conceitos como "ser", "sujeito" ou 'razão". Especificamente no campo jurídico, podem ser apontados como parte da semântica, entre outros, os conceitos de "dever", "sanção" ou "direito subjetivo". Quando um jurista afirma que uma pessoa tem direito subjetivo a um imóvel (ou seja, tem a propriedade do imóvel), está, de forma resumida, trazendo à baila uma série de poderes e deveres que a tradição jurídica ao longo dos tempos atribuiu àquele tipo específico de situação. Com isso, pode descrever de forma simplificada uma situação complexa, facilitando o encaminhamento das discussões futuras a respeito do tema. É nesse sentido que se afirma ser a semântica um tipo específico de estrutura voltada às observações realizadas pelo sistema.

Como já referido anteriormente, este estudo pretende relacionar determinadas modificações na semântica jurídica (as teorias imperativista e pragmática da norma jurídica) a determinadas modificações na estrutura social (a modernização da sociedade e a positivação do Direito, como se verá a seguir). Para esse efeito, a semântica será identificada com a teoria do direito, especificamente a teoria da norma jurídica. Já no lado da estrutura social, será necessário traçar uma nova distinção, a fim de demarcar dois planos de observação: de um lado, o plano mais geral da sociedade, de outro lado, o plano mais específico do sistema jurídico. Com isso, não se pretende criar uma oposição entre Direito e sociedade, visto que, segundo a teoria luhmanniana, o sistema jurídico integra o sistema social mais abrangente. Pretende-se tão-somente enfatizar as modificações estruturais por que passam esses dois sistemas. Desse modo, delimitam-se os três planos de observação que serão adotados: plano da sociedade, plano do Direito e, do lado da semântica, plano da teoria do Direito.

Cada um de tais planos apresenta características próprias que devem ser analisadas para a elaboração do modelo teórico que servirá à comparação das teorias imperativista e pragmática da norma jurídica. No plano da sociedade, o problema principal a ser analisado é a formação da sociedade moderna, mediante o processo de diferenciação funcional que se torna predominante a partir do final do século XVIII e início do século XIX. Já no plano do Direito, a questão que se apresenta é o processo de positivação, que se desenvolve simultaneamente à 
diferenciação funcional da sociedade (em verdade, como se verá na sequência, modernização e positivação são diferentes aspectos de um mesmo fenômeno). Por fim, no plano da teoria do Direito, importa observar as diferenciações que passam a ser aplicadas entre diferentes aspectos ou dimensões do sentido.

Para se compreender a modernização da sociedade, é importante lembrar que, nos termos luhmannianos, a sociedade é o sistema que contém todas as comunicações e, consequentemente, todos os sistemas que se valem de comunicações. Como tal, esse sistema enfrenta um grau de possibilidades muito maior do que aquelas efetivamente realizadas (pense-se na diferença entre tudo aquilo que poderia ser dito ou escrito e aquilo que efetivamente é dito ou escrito). Esse excesso de possibilidade é referido pela teoria dos sistemas como complexidade. A fim de lidar com sua alta complexidade interna, a sociedade cria estruturas e as ordena de acordo com determinados princípios (também eles, estruturas da sociedade). Esses princípios podem ser referidos como regras de diferenciações primárias da sociedade. As regras de diferenciação primárias da sociedade são as estruturas mais gerais do sistema, que determinam a forma como se criarão as demais estruturas sociais.

Com base no exemplo empírico-histórico, Luhmann identifica quatro formas de diferenciação primária. A primeira e mais simples é a diferenciação segmentada, que implica a criação de subsistemas idênticos entre si. Exemplo dessa forma de diferenciação são as sociedades primitivas, organizadas em clãs ou tribos. Já um pouco mais complexas são as sociedades organizadas de acordo com a distinção centro/periferia, em que se distinguem dois subsistemas: de um lado, o centro urbano, que adota uma estrutura hierárquica, e, de outro lado, a periferia rural, que se mantém organizada de modo segmentado. Essa é a estrutura encontrada nos grandes impérios territoriais, como o Império Romano, o Império Chinês e o Império Persa. O aumento da complexidade social só é possível pela completa hierarquização da sociedade, que ocorre nas sociedades organizadas pelo princípio da estratificação. Essas sociedades diferenciam dois subsistemas sociais em relação hierárquica, o estamento nobre e o estamento plebeu, separados entre si pela endogamia e por regras diferentes de conduta e comunicação. O principal exemplo apontado por Luhmann com relação a esse modelo de sociedade é a Europa medieval. Por fim, a forma de diferenciação que admite maior grau de complexidade é a diferenciação funcional, em que os sistemas diferem entre si em razão de cada um deles adotar uma perspectiva específica para observação da sociedade (isto é, cada um possui sua própria função). Na sociedade funcionalmente diferenciada, existe uma pluralidade de subsistemas, tratando cada um de um problema específico da complexidade social.

Segundo Luhmann, a diferenciação funcional surge uma única vez na história da humanidade: na Europa do final do século XVIII e início do século XIX. A partir daí essa forma de estruturação social espalha-se pelo mundo, seja por meio do comércio, da colonização ou do intercâmbio cultural. É em esses termos que o autor sustenta a existência atual de uma única sociedade no planeta: a sociedade mundial, diferenciada funcionalmente, que é por ele identificada com a sociedade moderna. Modernização, assim, para Luhmann, pode ser tomada 
como sinônimo de diferenciação funcional.

De acordo com a teoria dos sistemas, a modernidade caracteriza-se por atribuir a cada subsistema uma única e exclusiva função. Tendo em vista que os sistemas se diferenciam entre si exatamente por suas funções, não seria possível que algum deles exercesse mais de uma função. No caso do Direito, Luhmann não hesita em afirmar que a função desse sistema é a manutenção de expectativas de modo contrafático. Rejeita, assim, a concepção comum do Direito como instrumento de mudança social, isto é, de determinação de condutas. Para ele, em um ambiente tão complexo quanto a sociedade moderna, o sistema jurídico não é capaz de garantir, ao mesmo tempo, a motivação para a efetiva conduta dos indivíduos e a permanência de expectativas frustradas. Desse modo, o Direito abandona as primeiras (as condutas) e restringe-se às segundas (as expectativas), procurando determinar quais estruturas sociais prevalecem quando frustradas e quais devem ser substituídas uma vez que se verifiquem desvios. Nesses termos, passa a exercer o papel de controle último das variações admissíveis dentro da sociedade, atuando como sistema imunológico social.

Já no plano do Direito, a questão emergente é o processo de positivação por que passa o sistema jurídico. Positivação deve ser entendida como a transformação do Direito em Direito Positivo. O conceito de positividade do Direito tem sido identificado, pelo pensamento jurídico tradicional, com a instituição da decisão como fonte de validade das normas. Assim, toda norma positiva é fruto de uma decisão. De acordo com a teoria dos sistemas, essa concepção não é errada, mas incompleta: segundo Luhmann, a norma não só se torna válida em virtude de decisão, mas também assim permanece por força de decisão, qual seja, a decisão de não a revogar. Positividade, nesses termos, deve ser entendida como a possibilidade de variabilidade estrutural do Direito. Com esse alerta, põe-se em destaque que positivo é o Direito capaz de alterar-se a si próprio de acordo com suas próprias regras.

O processo de positivação, nos termos acima comentados, exige mudanças estruturais no Direito. Essas mudanças implicam a diferenciação entre dois tipos de processos: de um lado, os processos que visam a decisões que introduzem novas normas (decisões programantes, que resultam de processos programantes) e, de outro lado, os processos que visam a decisões que aplicam as normas já existentes no sistema (decisões programadas, que decorrem de processos programados). É essa diferenciação que permite ao Direito não só aplicar suas próprias regras, mas também modificar a si mesmo sem identificar as novas regras como desvios em relação àquelas anteriormente postas. A diferenciação de processos programantes e programados, portanto, é pressuposto e condição da positividade do Direito.

A positividade implica, ainda, a formação do Direito como um subsistema funcional da sociedade moderna. Com efeito, o surgimento de processos específicos para a alteração jurídica das normas jurídicas exige a instituição de controle jurídico sobre os próprios atos jurídicos. Em termos luhmannianos, os processos programantes causam a aplicação recursiva da diferença lícito/ilícito, por meio da qual a teoria dos sistemas 
identifica o Direito, aos atos do próprio sistema jurídico, dando origem ao controle, pelo sistema jurídico, de sua própria validade. Como referido no início desta seção, a aplicação recursiva de uma diferença em um dos lados dessa mesma diferença é o que caracteriza o conceito de sistema para Luhmann. Desse modo, com a positivação — e somente com ela — o Direito assume propriamente a forma de um subsistema na sociedade.

Por fim, o último plano de observação adotado neste estudo é o plano da teoria do Direito, em que se destaca a questão da decomposição analítica do sentido. A teoria do Direito, como mencionado acima, é vista por Luhmann como uma forma de fixação de sentido que reduz a complexidade ao destacar similitudes entre o fato em questão e fatos pretéritos (em termos luhmannianos: ao gerar redundância no sistema). A teoria do sistema identifica três dimensões distintas existentes em todo evento com sentido: a dimensão temporal, a dimensão material e a dimensão social.

A dimensão temporal está baseada na diferença antes/depois, que se generaliza por meio da diferença passado/futuro. Essa diferença institui o evento de sentido como um limite que altera o estado do sistema e marca, portanto, dois momentos: antes da alteração e depois da alteração. A dimensão temporal é especialmente importante no âmbito deste estudo por ser por meio dela que a teoria dos sistemas estabelece seu conceito de norma. Com efeito, na perspectiva temporal, Luhmann distingue dois tipos de expectativa: de um lado, aquelas que são abandonadas quando violadas; de outro lado, aquelas que se mantém, ainda que contra os fatos ocorridos. Às primeiras, denomina expectativas cognitivas ou cognições. Às últimas, que se mantêm contra os fatos, designa expectativas normativas ou normas.

Já a dimensão material institui-se a partir da diferença isso/aquilo, que aponta para relações internas/externas ao sistema. Essa dimensão, logo se vê, aponta para algo tomado como um objeto, que pode ser observado em separado de todos os demais objetos circundantes ou em suas relações com esses outros objetos. $\mathrm{Na}$ dimensão material, Luhmann identifica quatro formas a serem assumidas pelas expectativas: (i) pessoas, que se vinculam ao corpo e à consciência de um indivíduo concreto, (ii) papéis, que se referem a um aspecto específico das relações entre determinadas pessoas e os demais, (iii) programas, que abordam uma conduta específica a ser adotada por qualquer pessoa, no exercício de qualquer papel, e (iv) valores, que são ordens gerais de preferência que auxiliam na formação e organização de expectativas no sistema. De acordo com a teoria dos sistemas, na modernidade, a principal forma adotada pelas normas jurídicas é a de programa, cujo grau de abstração é alto o suficiente para fornecer grande flexibilidade e, simultaneamente, baixo o suficiente para ainda permitir a operacionalidade do sistema.

A dimensão social, por sua vez, é constituída pela diferença entre duas perspectivas no processo comunicativo, aquela entre, de um lado, quem observa e, de outro lado, quem expressa uma informação, referidas por Luhmann como Ego/Alter. Essa dimensão decorre do fato de a comunicação, apesar de ser realizada sempre 
e exclusivamente pelos sistemas sociais, envolver necessariamente a observação da diferença entre a informação comunicada e a forma como ela é expressa. Essa dimensão tem relevância neste estudo por ser o âmbito dos processos comunicativos, entre cujas formas possíveis está a estrutura hierárquica característica das relações de poder. A partir da dimensão social, é possível decalcar os elementos com base em que Norberto Bobbio estrutura sua análise da teoria imperativista da norma jurídica: (i) emissor; (ii) destinatário; e (iii) estrutura lógica, que, em termos de teoria dos sistemas, pode ser entendida como forma de observação e, nesse sentido, indica o tipo de relação existente entre emissor e destinatário.

As três dimensões acima analisadas apresentam-se sempre em conjunto, sendo decompostas apenas para fins analíticos. Essa unidade implica a limitação de uma dimensão pela outra: a capacidade de alterações, por exemplo, na dimensão material restringe as possibilidades de alterações nas demais dimensões, uma vez que o caráter unitário do sentido exige a manutenção de compatibilidade entre todas as três dimensões. Assim, na expectativa já referida quanto à atenção dos alunos à fala do professor, é possível identificar uma dimensão temporal (antes do início da fala/depois do início da fala, que, no caso, determina a dispersão dos alunos/atenção dos alunos), uma dimensão social (a relação hierárquica professor/aluno, que reflete o par emissor de comunicação/observador de comunicação) e uma dimensão material (a própria relação de ensino, que pode ser representada pela distinção dentro da sala de aula/fora da sala de aula). Apesar de ser possível a modificação em apenas uma das dimensões, essa mudança tende a comprometer o significado e a validade da expectativa em questão. Se, por exemplo, ao invés da sala de aula, professor e alunos estivessem discutindo sobre futebol no corredor da escola (mudança na dimensão material), a hierarquia (dimensão social), se é que ainda existente, assumiria contornos mais tênues, assim como a normatividade da atenção à fala do professor (dimensão temporal) também restaria prejudicada. As três dimensões, portanto, possuem relativa dependência umas em relação às outras.

Segundo Luhmann, o grau de dependência entre as dimensões não é fixo, mas varia de acordo com a complexidade social. Assim, sociedades mais complexas, como a sociedade moderna, precisam de maior diferenciação entre as dimensões do sentido, a fim de tornar possíveis modificações em uma determinada dimensão sem necessariamente prejudicar as demais. Em resumo, a relação de limitação e compatibilidade entre as dimensões é dinâmica e ganha em complexidade e diferenciação com base no processo de diferenciação da sociedade.

Nesses termos, é possível redefinir a hipótese de trabalho deste estudo em termos luhmannianos. A uma variação estrutural representada pela diferenciação funcional da sociedade e pela positivação do Direito, ocorrida com o início da sociedade moderna, no final do século XVIII e início do século XIX, correspondem modificações no plano da semântica jurídica. Especificamente no que se refere à norma jurídica, essa modificação é a teoria 
imperativista, que se torna possível mediante o aumento da diferenciação entre as três dimensões do sentido: de um lado, a neutralização da dimensão material, o que implica afirmar que a norma pode ter qualquer conteúdo; de outro lado, porém, a vinculação entre as dimensões temporal e social, por meio da definição da normatividade com base em uma relação de poder. É esse modelo de análise que se pretende aplicar, de forma consistente, ao imperativismo e à pragmática jurídica, a fim de possibilitar a avaliação dos ganhos descritivos proporcionados por essas duas teorias da norma.

\section{BREVE ANÁLISE DA TEORIA IMPERATIVISTA}

Como já referido na introdução, o imperativismo pode ser caracterizado pela concepção da norma jurídica como uma vontade emitida por um superior a fim de dirigir a conduta de um seu inferior. Essa definição aponta para uma utilização específica das dimensões do sentido (conforme definição adotada na seção anterior) e baseia-se em pressuposições também específicas a respeito da função e da estrutura do Direito na sociedade. Antes, porém, de analisar tais aspectos de acordo com o modelo teórico proposto, convém apresentar brevemente ao leitor uma referência às origens e aos períodos de evolução da teoria imperativista da norma jurídica.

As origens do imperativismo podem ser buscadas na distinção entre comandos e conselhos, que permeia o pensamento jurídico europeu desde a Antiguidade. Com efeito, não era raro, nos períodos antigo e medieval, encontrar referências genéricas ao Direito como comando, seja derivado da natureza das coisas, seja por imposição divina. Essa tradição semântica é apropriada pelos jusnaturalistas modernos, e reinterpretada a partir da distinção teológico-filosófica entre racionalismo e voluntarismo, ou seja, entre ordenação do mundo de natureza racional-necessária ou de caráter voluntário-contingente. Enquanto parte dos jusnaturalistas, entre os quais se destaca Hugo Grócio, faz uma leitura racionalista do Direito, em que a norma jurídica é caracterizada como um comando da razão, sustentando, portanto, a existência de um Direito necessário e passível de elaboração pelo método dedutivo, em alguns autores, especialmente Thomas Hobbes, é possível notar o início da aceitação de um Direito contingente. Essa aceitação baseia-se na noção de que o conteúdo das normas jurídicas não é pré-definido pela reta razão, mas, ao contrário, é resultado de escolha pelo soberano, que ordena aos súditos o comportamento a ser seguido a fim de preservar a vida de todos. Essa idéia é bem representada pela famosa afirmação hobbesiana: auctoritas, non veritas, facit legem. O comando normativo, então, começa a ser identificado como símbolo de contingência, não mais como veículo da necessidade racional, abrindo espaço para o que mais tarde viria a ser o imperativismo.

É justamente com base na concepção hobbesiana do Direito que, dois séculos mais tarde, a teoria imperativista viria a encontrar sua primeira formulação completa. Para fins exclusivamente didáticos, é possível classificar o imperativismo em três fases: (i) fase clássica, que se concentra ao longo do século XIX; (ii) fase de 
transição, que pode ser demarcada entre a segunda metade do século XIX e a primeira metade do século XX; e, por fim, (iii) fase crítica ou moderna, que se inicia na primeira metade do século XX e se prolonga até os dias atuais. Cada uma dessas fases possui características próprias, que podem ser organizadas a partir dos pontos de observação do emissor da norma, do destinatário da norma e da estrutura lógica normativa.

O imperativismo clássico tem como seu principal expoente o inglês John Austin. Segundo esse autor, o conceito de comando é a chave para a compreensão das ciências morais e jurídicas. Por meio da combinação entre, de um lado, o conceito de comando e, de outro lado, a origem do comando, Austin consegue delimitar o campo de várias áreas da ação humana, identificando o Direito com o Direito Positivo, isto é aquele criado por um soberano para os membros da sociedade política independente na qual o soberano exerce sua superioridade política. A juridicidade, nesse modelo, depende claramente da posição de poder detida pelo emissor das normas. Dessa forma, a fase clássica da teoria imperativista pode ser caracterizada da seguinte forma: (i) com relação ao emissor, esse é identificado com o soberano, detentor último do poder político na sociedade; (ii) no que se refere ao destinatário, a norma é sempre dirigida aos súditos, que estão obrigados, em função da força do soberano, a cumpri-las; e, por fim, (iii) no que tange à estrutura lógica, o comando normativo aparece como uma ordem incondicional, direta, que não deixa margem de questionamentos a seus destinatários.

O modelo imperativista clássico não tardou a ser objeto de críticas em razão da dificuldade de sua aplicação aos processos concretos de criação e aplicação do Direito. Na fase de transição, essas críticas foram dirigidas a cada um dos elementos caracterizadores da teoria imperativista. Assim, no que tange ao emissor, Karl Olivecrona apontou para o fato de os procedimentos legislativos que levam à produção de novas normas não conterem, em qualquer momento, a expressão de um comando ou uma ordem à população. Antes disso, no que se refere aos destinatários, Jhering já havia pontuado que o comando normativo não pode ser dirigido aos cidadãos em geral, que raramente os conhecem, mas, ao contrário, destinam-se aos aplicadores do Direito, que efetivamente os adotam na sua tomada de decisões. Por fim, com relação à estrutura lógica, Adolfo Ravà aponta o caráter técnico do Direito a fim de rejeitar, para as normas jurídicas, a estrutura incondicional, propondo, em substituição, o modelo condicional se/então como a estrutura fundamental da norma.

Esses questionamentos ao modelo clássico da teoria imperativista levam, na fase moderna, a uma progressiva mitigação da ideia original de comando. Duas estratégias podem ser destacadas para alcançar esse objetivo: de um lado, a tentativa de afirmar o caráter metafórico do imperativismo, nos termos propostos por Kelsen, de outro lado, a busca de uma reformulação do significado da noção de comando, tentada por Bobbio. Não cabe aqui descer às minúcias da análise do pensamento desses dois autores. Importa somente destacar que seus esforços dirigiram-se ao desafio de incorporar as críticas apresentadas ao modelo clássico durante a fase de transição, esvaziando o sentido original da noção de comando e, ao mesmo tempo, preservando a abordagem 
imperativista ao problema da norma, bem como, na medida do possível, sua terminologia. Formularam, assim, uma teoria da norma com as seguintes características: (i) no que se refere ao emissor, apresenta um comando despsicologizado, ou seja, sem emissor definido; (ii) no que tange ao destinatário, dirige-se aos órgãos julgadores, não ao sujeito cuja conduta é regulada; e (iii) com relação à estrutura lógica, adota a concepção da proposição condicional, promovendo, portanto, um afastamento do comando com a conduta realizada. Logo se vê que muito pouco resta, no imperativismo crítico, da noção original de comando.

A conclusão que se alcança ao traçar a esse brevíssimo roteiro histórico da teoria imperativista é a de que a noção de comando mostra-se cada vez mais inadequada para descrever o fenômeno da norma jurídica. Se essa conclusão é correta, é inevitável indagar por que o imperativismo não foi simplesmente descartado e substituído por outra teoria da norma.

A fim de tentar buscar pistas para responder a essa questão, parece adequado recorrer ao modelo teórico apresentado na seção anterior para analisar sociologicamente os fundamentos do imperativismo. Desse modo, a análise será dividida nos três planos de observação deste estudo, quais sejam, o plano da sociedade, o plano do Direito e o plano da teoria do Direito. De acordo com a premissa teórica adotada, importa verificar como a teoria imperativista reflete, no plano da teoria do Direito, por meio da diferenciação das dimensões do sentido, as modificações estruturais ocorridas nos planos da sociedade e do Direito. Em consequência, será necessário analisar os pressupostos tomados pelo imperativismo com relação a esses dois planos estruturais antes de analisar especificamente a questão da diferenciação do sentido.

No plano da sociedade, a mudança estrutural marcante no final do século XVIII e início do século XIX é a predominância da diferenciação funcional como forma primária de diferenciação do sistema societário, o que, segundo Luhmann, caracteriza a modernidade. Essa evolução estrutural resulta nas tentativas da teoria imperativista de delimitar a área específica do Direito face às demais atividades humanas. Nesse esforço, porém, os autores imperativistas acabam por atribuir ao Direito não a função de manutenção de expectativas de modo contrafático, mas, ao invés, aquela tanto mais complexa de orientação das condutas dos indivíduos. Em decorrência dessa definição da função do Direito, o imperativismo internaliza na teoria da norma aquilo que a teoria dos sistemas denomina de problema de motivação, ou seja, a dificuldade de controlar a reação do interlocutor, a fim de que determinada comunicação seja aceita ou rejeitada como premissa das comunicações anteriores. Entende-se, então, o recurso frequente dos imperativistas ao conceito de sanção como elemento essencial à norma, visto que a sanção oferece um modo de lidar com a reação do destinatário. Sob essa perspectiva, a norma jurídica acaba por ser reduzida ao poder - esse sim um instrumento de manipulação da motivação, de acordo com a teoria luhmanniana —, uma vez que a norma nada mais é do que a vontade do agente (politicamente) mais forte. Em consequência, o imperativismo aponta a política, que está fora do Direito, 
como o fundamento do sistema jurídico, negando, pois, sua autorreferencialidade.

Já no plano do Direito, a mudança estrutural marcante é a positivação, que significa a possibilidade de alteração estrutural do Direito por si mesmo, mediante procedimentos autorregulados. Nesse plano, é necessário diferenciar as perspectivas interna e externa. Essa última importa a mudança da principal fonte de estímulo para a variação do Direito da moral para a política. Se, antes da positivação, a inexistência de procedimentos programantes (aqueles que inserem novas normas no sistema) fazia com que a mudança do Direito somente pudesse ser levada a cabo com base na reinterpretação de princípios morais, dando novo significado a regras há muito já conhecidas, após a positivação, o surgimento dos procedimentos programantes torna possível que uma decisão externa ao Direito — uma decisão política — modifique as condições decisórias do sistema jurídico, ao alterar os textos legais, premissas interpretativas com base nas quais o sistema toma suas decisões. Essa transferência da moral para a política provoca um aumento da contingência do Direito e, consequentemente, de sua complexidade interna.

Ainda no que se refere ao plano do Direito, a perspectiva interna aponta para o fato de os imperativistas adotarem os procedimentos programantes como enfoque para a descrição das normas. Isso significa que a norma jurídica é definida sempre do ponto de vista de sua criação, ao invés do ponto de vista de sua atuação no sistema. Uma consequência dessa abordagem é a confusão entre a norma e o ato que a cria. Com efeito, um comando é um fato delimitado no tempo (na terminologia da teoria dos sistemas, um evento). A norma jurídica, por sua vez, é uma estrutura, isto é, um significado que se prolonga no tempo ao se tornar disponível para comunicações futuras. Ao definir a norma como comando, o imperativismo viola essa diferença essencial entre fato e norma, evento e estrutura, e mascara, portanto, o funcionamento do próprio processo programante. Apresenta, pois, uma descrição reducionista do fenômeno que pretende descrever.

Por fim, no plano da teoria do Direito, a teoria imperativista deve ser analisada com base na diferenciação das dimensões do sentido. Nessa teoria da norma, a diferenciação ocorre de modo parcial: enquanto a dimensão material é neutralizada, o que importa dizer que o conteúdo das normas não é mais relevante para definir sua normatividade, as dimensões social e temporal permanecem vinculadas, em razão de a normatividade ser definida com base na relação de poder (dimensão social) existente entre emissor e destinatário. Essa vinculação implica adotar a relação de subordinação como fundamento para toda a juridicidade, restringindo as formas de criação do Direito apenas àquelas de caráter hierárquico e desprezando os procedimentos de natureza coordenativa, como, por exemplo, a negociação contratual entre partes - ao menos juridicamente - iguais. Com isso, o sistema perde flexibilidade e reduz sua complexidade interna.

Em resumo, é possível afirmar que a teoria imperativista caracteriza-se pela fundamentação da normatividade na dimensão social do sentido das normas, mantendo atreladas, portanto, as dimensões social e 
temporal, simultaneamente à neutralização da dimensão material. Essa forma de diferenciação do sentido refletese, no plano do Direito, na adoção dos procedimentos de criação de normas como perspectiva de definição da norma jurídica, bem como, no plano da sociedade, na internalização da orientação de condutas como função principal do Direito.

Após esse breve resumo dos principais aspectos sociológicos do imperativismo, a próxima seção buscará aplicar o mesmo modelo de análise teórica à teoria pragmática.

\section{A TEORIA PRAGMÁTICA DA NORMA JURÍDICA}

Se as tentativas imperativistas de descrição da norma jurídica apresentam as limitações comentadas na seção anterior, a teoria pragmática buscará superá-las por meio da abordagem do Direito como discurso33, entendido este, nos moldes da cultura ocidental tradicional, como um fenômeno intersubjetivo composto de ações linguísticas, isto é, ações dirigidas ao entendimento de outrem. Nesses termos, Tercio Sampaio Ferraz Jr. pretende formular uma análise geral do discurso jurídico em seu "Direito, retórica e comunicação", enquanto dedica sua "Teoria da norma jurídica" à aplicação específica do discurso normativo. São esses dois livros, pois, que constituirão o cerne da análise deste artigo.

Para buscar compreender o discurso jurídico, Ferraz Jr. adota uma perspectiva pragmática. Essa perspectiva decorre dos estudos semióticos, em que a linguagem é decomposta em três momentos: sintática, semântica e pragmática. De modo bastante esquemático, é possível afirmar que, enquanto a sintática ocupa-se da relação entre os elementos do discurso entre si e a semântica encarrega-se da relação entre os elementos linguísticos e os objetos reais por eles representados, a pragmática refere-se à relação existente entre o discurso e o contexto em que é proferido, apontando, portanto, para a relação existente entre orador e ouvinte. Isso implica afirmar que a análise pragmática enfoca o discurso — aí incluído o discurso da norma jurídica — sob uma perspectiva designada pela teoria dos sistemas como dimensão social do sentido. Assim, para efeitos do modelo teórico escolhido para este artigo, deve-se notar, de partida, que a pragmática jurídica constitui uma análise essencialmente social do discurso jurídico, no sentido de que pretende compreendê-lo como um conjunto de ações entre duas partes, orador e ouvinte, emissor e destinatário, ou, mais genericamente, em termos luhmannianos, Alter e Ego.

A partir dessa noção, delineiam-se, sob a perspectiva pragmática, os elementos e a regra geral de todo discurso. Sendo uma análise social do fenômeno discursivo, é natural que a pragmática decomponha o sentido

\footnotetext{
${ }^{3}$ Como expressamente alerta o autor, a escolha do discurso jurídico como objeto de análise não implica, contudo, a afirmação de que o Direito possa ser reduzido a um discurso, nem que devam ser descartadas outras formas de abordagem ao complexo fenômeno jurídico. A limitação da análise ao caráter discursivo do Direito trata-se, simplesmente, de um recurso metodológico, não de uma opção ontológica a respeito do objeto de estudo. (Ferraz Jr., 1997: XIII).
} 
nos seguintes três elementos: (i) o orador, que emite o discurso; (ii) o ouvinte, a quem o discurso é dirigido; e, por fim, (iii) o objeto, que consiste na própria informação emitida. Se se tomar o objeto em sentido formal, isto é, abstraindo-se de seu conteúdo concreto, é notável a semelhança com os três elementos apontados por Bobbio como fundamentais para a análise do imperativismo. Enquanto o orador ocupa o lugar do emissor, o ouvinte exerce o papel do destinatário e o objeto representa a estrutura lógica. Reforça-se, desse modo, a percepção de que a comparação entre essas duas teorias da norma jurídica pode apresentar resultados frutíferos.

Já no que tange à regra geral que ordena os elementos discursivos, essa deve ser encontrada no dever de prova. Essa regra deve ser compreendida como a atribuição, a todo aquele que fala, da responsabilidade por justificar aquilo que é dito. É a partir dessa regra que Ferraz Jr. pretende estabelecer ligações entre, de um lado, a pragmática jurídica e, de outro lado, não só a ética, uma vez que se compreenda o dever de fundamentação como um dever moral, mas também a racionalidade, por meio da identificação do discurso racional com o discurso fundamentante, isto é, aquele que se sujeita a apresentar fundamentos para suas afirmações. Essas ligações, no entanto, ultrapassam os limites da análise deste estudo. Para esses fins mais restritos, importa destacar que, ao contrário do modelo de comando que marca o imperativismo, especialmente em sua fase clássica, a pragmática jurídica inclui em sua análise a reação do ouvinte sobre a mensagem emitida pelo orador. Com efeito, como visto na seção anterior, o modelo clássico do imperativismo identifica a norma com uma ordem emitida pelo soberano para seus súditos, apresentando, portanto, uma visão "ex parte principis" da norma jurídica. Ao admitir, com base no dever de prova, a possibilidade de o orador vir a ser questionado por sua afirmação e, assim, ver-se obrigado a justificá-la, a pragmática, ao contrário, leva em consideração a forma como o ouvinte reage à ação do orador, incorporando, portanto, em sua análise a reflexividade ou autorrecursividade inerente à situação comunicativa.

É justamente com base no dever de prova que se estabelecem as duas possíveis estruturas do discurso. De um lado, há discursos ditos dialógicos, em que o ouvinte está habilitado a intervir na fala do orador. Pense-se nos debates legislativos, em que os parlamentares discutem entre si a respeito da aprovação ou rejeição de determinada proposta, ou, em um nível mais prosaico, nas conversas quotidianas entre amigos. De outro lado, porém, há discursos chamados de monológicos, em que o ouvinte não está habilitado a intervir. É o caso de uma palestra, especialmente se proferida por um pesquisador em um congresso científico, em que não seria adequado aos participantes interromper a fala do orador a fim de apresentar objeções ao que foi dito. Essa limitação, todavia, não implica desconsideração do dever de prova, visto que a relativa isenção do dever de prova é compensada por outras formas de controle por parte dos ouvintes (no exemplo acima, a tese apresentada pelo pesquisador poderia ser rejeitada pela banca examinadora do congresso ou, ainda, ser objeto de contestação em pesquisas subsequentes).

Da diferença acima pode-se notar que, para além da regra geral do dever de prova, os discursos dialógicos 
e monológicos estão sujeitos a regras específicas, somente a eles aplicáveis. Assim, no discurso dialógico, todos os atos do orador podem ser questionados. Em consequência, os pontos de partida adotados pelo orador não devem ser atacados pelo ouvinte, sob pena de o orador defendê-los, exigindo justificação ao próprio questionamento que the é apresentado. Em compensação, porém, o orador deve manter-se fiel a seus pontos de partida, se não quiser sofrer objeções por parte dos ouvintes. O objeto do discurso dialógico é, portanto, uma questão conflitiva, designada por Ferraz Jr. de "dubium", cuja reflexividade pode levar a aporias.

Já no discurso monológico, por sua vez, nem todos os atos de fala podem ser atacados. Dessa forma, os atos do orador devem ser divididos em atacáveis e atos não-atacáveis. Não-atacáveis são os atos com relação aos quais o orador dispõe de justificativas para defendê-los; atacáveis, ao contrário, são aqueles que não contam com tal possibilidade de defesa. Assim, enquanto os atos não-atacáveis podem ser propostos sem sujeitar-se a justificativa, os atos atacáveis não podem ser sequer propostos pelo orador. Transfere-se, desse modo, ao orador a responsabilidade pelo controle prévio de suas asserções. O objeto do discurso monológico é, nesses termos, uma questão com sua reflexividade interrompida, designada por Ferraz Jr., de "certum", admitindo, por essa razão, sua axiomatização.

Para além das duas possíveis estruturas do discurso, é possível também diferenciar, ainda em função da relação entre orador e ouvinte, dois modos do discurso. No primeiro, designado homológico ou discussão-com, orador e ouvinte estão em posições simétricas, o que gera cooperação entre as partes, que adotam, em relação ao objeto discursivo, uma estratégia de convencimento, baseada na conviç̧ão. Já no segundo modo, designado heterológico ou discussão-contra, orador e ouvinte estão em posições assimétricas, o que leva à tomada de posições partidárias em relação a um objeto que se apresenta como conflito, ou seja, como alternativas incompatíveis, causando a adoção de estratégias de persuasão como controle do discurso, visando a uma decisão. De acordo com Tercio Sampaio Ferraz Jr., se, por um lado, os discursos homológicos podem ser encontrados tanto em estruturas dialógicas quanto em estruturas monológicas, os discursos heterológicos, por outro lado, estão confinados ao âmbito das estruturas dialógicas, não se admitindo discussão-contra monológica, em função da incompatibilidade entre as regras aplicáveis a esse modo e estrutura do discurso.

É por meio das diferenças dialógico/monológico e homologia/heterologia que o autor pretende analisar o discurso jurídico de um modo geral, bem como o discurso normativo em particular. Para aplicá-las, parte da premissa de que o Direito seria marcado pela bilateralidade e pela exigibilidade. A bilateralidade, qualidade compartilhada com outros discursos sociais, seria uma decorrência do fato de os comunicadores jurídicos assumirem simultaneamente os papéis de orador e ouvinte, emissores e destinatários. Nesses termos, o discurso jurídico seria um exemplo de discurso dialógico. A especificidade que o distinguiria em tal gênero seria justamente a exigibilidade, que consiste na possibilidade de um participante exigir uma determinada comunicação pelo outro 
em caso de recusa. Essa característica da situação comunicativa jurídica faria com que as partes assumam papéis ativos e reativos, de forma partidária. Trata-se, portanto, de um discurso heterológico (discussão-contra), em que se aplicam técnicas persuasivas visando à obtenção de uma decisão. Essa decisão ocorre, no Direito, pela intervenção, como árbitro, de um terceiro, cujo papel é exercido, genericamente, pela norma jurídica. $\mathrm{O}$ terceiro não pode eliminar o "dubium", ou seja, convertê-lo em um "certum", mas, por sua posição institucionalizada, pode terminá-lo, isto é, impedir que o conflito continue, uma vez que é capaz de institucionalizar o próprio conflito, estabelecendo, desse modo, parâmetros para seu desenvolvimento. Essa institucionalização, contudo, revela o caráter reflexivo do discurso jurídico: a norma, que decide o conflito, é ela própria também objeto de decisão. A fim de lidar com essa reflexividade, o discurso jurídico pode assumir várias formas, entre as quais o autor destaca, na perspectiva da metalinguagem, o discurso da ciência do Direito, na perspectiva da aplicação normativa, o discurso judicial e, por fim, na perspectiva da produção normativa, o discurso normativo.

Assim, de acordo com a pragmática jurídica, a norma é analisada essencialmente como discurso normativo. Esse discurso não se limita ao discurso legislativo, que é uma sua subespécie, mas inclui todos os discursos que estabelecem normas. Fica patente, nesses termos, que, assim como a teoria imperativista da norma jurídica, a pragmática de Tercio Sampaio Ferraz Jr. adota os processos programantes (ou seja, aqueles que visam à inserção de novas normas no sistema) como perspectiva privilegiada para a conceituação da normatividade. Isso significa que imperativismo e pragmática alinham-se quanto ao enfoque para a definição da norma jurídica, que acentua o momento de sua criação sobre o momento de sua aplicação. Privilegia-se, assim, análise genética sobre análise funcional, o que, como já referido acima com relação ao imperativismo, prejudica uma completa distinção entre a norma jurídica e o fato que a origina.

Avançando, porém, com a conceituação pragmática da norma jurídica, é importante relembrar que o discurso jurídico - e, portanto, o discurso normativo, que é um subtipo do discurso jurídico — caracteriza-se essencialmente pela inserção do terceiro, que garante a decidibilidade do conflito entre orador e ouvinte, como forma de permitir a exigibilidade. Nesse contexto, o que especifica o discurso normativo é a ambiguidade estrutural decorrente da posição do terceiro em relação às partes. Essa ambiguidade decorre do fato de as discussões relativas à aprovação da norma transcorrerem sob uma estrutura dialógica, em que os envolvidos têm garantidas amplas possibilidades de intervenção. Tomada a decisão, entretanto, a regra escolhida assume uma posição de superioridade sobre as partes, posição essa que não pode ser questionada, em termos semelhantes a uma estrutura monológica. Essa superioridade é caracterizada por Ferraz Jr. como uma relação de metacomplementaridade entre a regra de decisão e as partes em conflito, de modo que as partes estão, com relação uma à outra, sob uma estrutura dialógica, mas, com relação à regra, sob uma estrutura monológica. É a ambiguidade decorrente da metacomplementaridade que, segundo a pragmática jurídica, caracteriza o discurso 
normativo.

A fim de analisar especificamente o sentido dessa relação metacomplementar, Ferraz Jr. introduz uma nova distinção, qual seja, aquela entre cometimento e relato. Se as diferenças anteriores, relativas à estrutura e ao modo do discurso, estavam centradas na reação do ouvinte à ação linguística do orador, a nova distinção refere-se especificamente ao plano do objeto do discurso. Nem por isso, todavia, ela se refere à dimensão material, ao conteúdo de tal objeto, como seria de se esperar se se tratasse de uma teoria de cunho jusnaturalista. Permanecendo no plano abstrato-formal, a distinção cometimento/relato refere-se a dois níveis de informação: enquanto o relato é a informação que se pretende transmitir ao ouvinte, o cometimento é uma informação sobre como essa informação (relato) deve ser interpretada. Tome-se, por exemplo, como um possível relato, a frase "você deve melhorar sua caligrafia". Dirigida por um professor a um aluno, pode ser entendida como uma ordem. Já se dirigida a esse mesmo aluno por um colega, parecerá mais com uma reprovação. Assim, ainda que nem sempre o apresente de forma explícita, toda comunicação contém, além do nível relato, um nível adicional, o cometimento, que informa ao ouvinte como deve interpretar a informação transmitida.

Quando inserida no contexto de análise da reação do ouvinte ao ato do orador, como aquele proposto pela pragmática jurídica, a distinção cometimento/relato pode dar origem a três diferentes resultados. De uma parte, é possível ao ouvinte aceitar o cometimento e o relato da comunicação expressa. No exemplo acima, o aluno concorda com a reprimenda e promete esforçar-se para escrever melhor. Essa situação é designada confirmação. De outra parte, é possível também ao ouvinte aceitar o cometimento, mas negar o relato. Ainda no mesmo caso, o aluno apresentaria uma justificativa razoável para a caligrafia apresentada, por exemplo, estar com um dedo quebrado. Nesse passo, ele aceita a posição do orador, mas recusa o conteúdo comunicado. Esse é o caso de uma negação. Por fim, é possível ao ouvinte rejeitar o cometimento, sem sequer entrar no mérito do relato. Voltando ainda uma vez ao exemplo acima, o aluno poderia responder: "quem você pensa que é para falar da minha caligrafia?". Nesse caso, é a própria posição assumida pelo orador, isto é a informação sobre a informação, que é negada. É nessa situação que se fala em desconfirmação. A partir da reação do ouvinte, portanto, a distinção cometimento/relato pode ser desdobrada na diferença confirmação/negação/desconfirmação.

Especialmente importante para a análise do discurso normativo sob a abordagem da pragmática jurídica é a desconfirmação. Como explicado acima, a desconfirmação implica a rejeição de uma posição pressuposta pelo orador no processo comunicativo. Em termos luhmannianos, essa pressuposição pode ser identificada com uma expectativa, visto que representa uma generalização de sentido (o sentido da posição do orador) proveniente de atos passados e ainda disponível para comunicações presentes. Nos termos descritos na seção 2 deste artigo, diante de uma frustração, tal como uma desconfirmação, as expectativas devem adotar, na perspectiva temporal, 
uma dentre duas possibilidades: ou serem descartadas, ou permanecerem, mediante a adoção de um procedimento específico destinado a esse fim. Na primeira hipótese, trata-se de uma expectativa cognitiva. Seria o caso se o comentário a respeito da caligrafia do aluno tivesse sido feito por um colega; este não teria recurso contra o mau calígrafo, salvo manter uma distância razoavelmente segura, a fim de evitar novos conflitos. Já na segunda hipótese, em que a expectativa frustrada permanece, trata-se de uma expectativa normativa. Seria o caso se o comentário tivesse sido feito por um professor, que poderia manifestar a permanência de sua expectativa dando ao aluno uma advertência pelo ato de indisciplina.

É a partir das observações acima que se pode compreender o conceito de metacomplementaridade. Dos exemplos empregados, parece claro que alguns tipos de situação comunicativa permitem ao orador resistir ao ataque a seu cometimento. Nesses casos, ao orador é possível desconfirmar a desconfirmação, insistindo, contrafaticamente, na sua posição perante o ouvinte. É justamente esse tipo de relação que Ferraz Jr. designa de metacomplementar. A capacidade de desconfirmação da desconfirmação torna a posição de superioridade a regra de decisão, pois permite que ela desafie eventuais contestações, prevalencendo sobre sua frustração. Daí a ambiguidade estrutural que caracteriza o discurso normativo: no plano do relato, vigora uma estrutura dialógica, em que o orador ou emissor busca persuadir os ouvintes ou destinatários, que, por sua vez, exercem papel ativo, na discussão a respeito do conteúdo da norma (interpretação normativa); já no plano do cometimento, ao contrário, aplica-se uma estrutura monológica, em que o orador ou emissor impõe sua posição de superioridade sobre os ouvintes ou destinatários, que são reduzidos a um papel meramente passivo.

Sob uma perspectiva luhmanniana, conforme explicitada nas seções anteriores deste artigo, não se pode deixar de notar a forma como a pragmática jurídica relaciona as dimensões temporal e social do sentido por meio da vinculação entre normatividade e cometimento. Se, de um lado, nos termos acima referidos, a pragmática assemelha-se ao imperativismo ao abstrair a dimensão material por meio de uma análise formal que desdobra o objeto da discussão normativa em dois planos abstratos (cometimento/relato), sem recurso ao controle do conteúdo do discurso, por exemplo, por critérios de justiça ${ }^{4}$, de outro lado, afasta-se do imperativismo ao distinguir claramente os aspectos social - a relação entre as partes, representada pelo cometimento - e temporal — a reação do orador à desconfirmação do ouvinte, que pode ser também ela desconfirmada. Com efeito, como analisado na seção anterior deste estudo, uma das características marcantes do imperativismo é a definição da normatividade a partir da perspectiva social, com base na superioridade do emissor da norma.

Essa distinção, porém, não é suficientemente drástica para cortar os laços entre as duas dimensões do

\footnotetext{
${ }^{4}$ Esse controle, porém, reaparece na teoria pragmática da norma sob forma da discussão da legitimidade e racionalidade do discurso. Conforme brevemente mencionado no início desta seção, para Tercio Sampaio Ferraz Jr., a legitimidade decorre da racionalidade, que, por sua vez, caracteriza-se por um critério procedimental, qual seja, a sujeição à regra do dever de prova. Assim,
} vol.10, nº. 04, Rio de Janeiro, 2017.pp. 2257-2278 
sentido acima referidas. É o que se percebe quando se considera o fato de que a normatividade (dimensão temporal) aparece vinculada, na teoria pragmática da norma jurídica, não propriamente à regra de decisão (ao programa decisório, em termos luhmannianos), mas à posição de superioridade de seu emissor. A desconfirmação, de fato, aparece, no modelo pragmático, como um ataque à impostação assimétrica conferida pelo orador à sua relação com o ouvinte. Desse modo, apesar de avançar em relação ao imperativismo, ao distinguir as dimensões social e temporal na norma jurídica, a pragmática reafirma a prioridade teórica da primeira em relação à segunda, ao estabelecê-la como intermediária entre a normatividade e a regra de decisão propriamente dita.

Para além da definição da norma jurídica, um último tema que merece ser comentado com relação à teoria pragmática de Ferraz Jr. é sua tentativa de redefinir os atributos das normas, por meio da qual se torna possível o controle das situações comunicativas normativas umas em relação às outras. Para esse efeito, destaca-se, além dos conceitos clássicos de validade e efetividade, a elaboração, pelo autor, do conceito de imperatividade ou obrigatoriedade. Assim, a validade é concebida como uma forma de imunização do cometimento de uma norma pelo relato de outra norma, que the é figurativamente referida como superior. A efetividade, por sua vez, é formulada como uma forma de adequação do cometimento e do relato de uma mesma norma. Já a imperatividade, por fim, é totalmente despida da concepção imperativista do comando para ser entendida como a relação de calibração entre o cometimento de uma norma (superior) e o cometimento de outra norma (inferior). Nesses termos, aparece como uma forma de estabilização dos cometimentos, regulando as relações entre oradores-emissores e ouvintes-destinatários e instaurando os padrões de validade que deverão ser obedecidos dentro de cada cadeia normativa.

A análise acima apresentada da teoria pragmática da norma jurídica parece fornecer os elementos necessários à comparação dessa teoria com o imperativismo, de acordo com o modelo teórico fornecido pela teoria geral dos sistemas luhmanniana, resumido na seção 2 deste artigo. Para fins dessa comparação, será útil recorrer novamente aos três planos de observação definidos no início deste estudo, verificando a forma como essas teorias refletem, no plano da teoria do Direito, as modificações estruturais ocorridas nos planos da sociedade e do Direito.

Assim, no que se refere ao plano da sociedade, é possível afirmar que tanto a teoria pragmática quanto o imperativismo pressupõe para o Direito uma função de orientação de condutas. Enquanto na teoria imperativista essa orientação dá-se no plano fático, mediante a obediência do destinatário ao comando do soberano, na pragmática jurídica ela ocorre no plano simbólico, por meio do controle, pelo orador-emissor, das reações possíveis do ouvinte-destinatário no âmbito do discurso normativo. Com esse deslocamento para o plano 
simbólico, a pragmática atenua a necessidade de internalização do problema da motivação na teoria da norma, ainda que o problema da reação do ouvinte continue presente, em decorrência da própria abordagem situacional que caracteriza essa teoria.

Já no que tange ao plano do Direito, sob uma perspectiva externa, ambas as teorias da norma conseguem refletir a contingência normativa decorrente da positividade jurídica. Se, de um lado, o imperativismo remete o problema da formulação das novas regras para à política, negando espaço de controle pela moral, a teoria pragmática alcança resultados similares ao admitir a estrutura dialógica para a fase de discussão quanto ao conteúdo das novas normas. Dessa forma, permite a procedimentalização do processo programante (criação de normas), sem recorrer a um controle de conteúdo com base em critérios axiológicos, típicos de uma abordagem jusnaturalista.

Ainda no plano do Direito, sob a perspectiva interna, a diferenciação entre processos programantes, de criação de novas normas, e processos programados, de aplicação de normas já existentes, é reconhecida tanto pela pragmática quanto pelo imperativismo. Mais além, ambas as teorias adotam o processo programante como perspectiva de definição da norma, o que, nos termos já referidos acima, acarreta dificuldades em diferenciar, de um lado, a norma e, de outro lado, a decisão (fato) que a insere no sistema.

Por fim, no tocante ao plano da teoria do Direito, é possível notar a neutralização da dimensão material da norma (conteúdo) nas duas teorias; no entanto, enquanto o imperativismo mostra-se incapaz de diferenciar as dimensões social e temporal, promovendo uma definição da normatividade com base na relação social hierárquica entre as partes, a teoria pragmática realiza tal distinção ao separar o cometimento (dimensão social) da expectativa mantida pelo orador a respeito dele (dimensão temporal). Os efeitos dessa separação, contudo, são mitigados pelo fato de essa teoria admitir a normatividade como manutenção não da regra de decisão em si, que permanece no plano do relato, mas, ao contrário, da expectativa a respeito da relação entre as partes, que se situa no nível do cometimento. Com isso, ainda que segregue as duas dimensões, a pragmática jurídica dá maior ênfase teórica à dimensão social que à temporal, onde, segundo a teoria dos sistemas luhmanniana, radica o problema da normatividade.

\section{CONCLUSÃO}

A comparação entre a pragmática jurídica e a teoria imperativista parece confirmar a pressuposição inicial de que a primeira não pode ser entendida como uma subespécie ou mesmo uma reformulação da segunda. Com efeito, a pragmática apresenta, na compreensão da normatividade jurídica, avanços significativos em relação à tradicional teoria imperativista, representados pela distinção, no plano da teoria do Direito, entre a 
normatividade e a situação social das partes envolvidas na produção da norma.

Em que pese tais avanços, é preciso reconhecer que ambas as teorias compartilham similaridades com relação à forma de abordagem do problema da norma jurídica: tanto a pragmática quanto o imperativismo assumem, ainda que em diferentes graus, a orientação de condutas como função pressuposta para o Direito, além de que ambas escolhem os processos de criação normativa como perspectiva para a definição do conceito de norma. Essa similaridade de enfoque acaba por limitar o impacto teórico da distinção entre as dimensões social e temporal do sentido na teoria pragmática da norma jurídica, apresentando, em consequência, limitações para a descrição da norma em conformidade com a teoria geral dos sistemas. Nesses termos, uma teoria jurídica da norma coerente com a proposta luhmanniana permanece uma tarefa a ser cumprida.

\title{
THE PRAGMATIC THEORY OF LEGAL NORMS AND IMPERATIVISM: AN ANALYSIS BASED ON THE SOCIOLOGY OF LUHMANN
}

\begin{abstract}
This paper compares the legal pragmatics proposed by Tercio Sampaio Ferraz Jr. and positivistic legal imperativism, from the standpoint of the self-referential system's theory. The comparison moves in three levels: the level of society, the level of law, and the level of legal theory. At the first level, legal pragmatics shares, in a mitigated form, the imperativistic view of the function of law as guidance to conduct. At the second level, legal pragmatics follows the imperativistic approach in analyzing legal norms in the perspective of its creation, rather than its application. Finally, at the level of legal theory, legal pragmatics goes beyond imperativism by distinguishing the social and temporal aspects of normativity, but it fails to explore this distictions due to the theoretical approach taken at the previous levels.
\end{abstract}

Keywords: Legal Rules; Imperativism; Legal Pragmatics; Legal Positivismo; Systems' Theory.

\section{REFERÊNCIAS BIBLIOGRÁFICAS}

AUSTIN, John, 1998: The province of jurisprudence determined and the uses of the study of jurisprudence. Indianapolis/Cambridge: Hackett Publishing Company.

BARALDI, Cláudio, CORSI, Giancarlo,ESPOSITO, Elena, 2002: Luhmann in glossário - I concetti fondamentali della teoria dei sistemi sociali, $4^{a}$ ed., Milano, Franco Angeli.

BOBBIO, Norberto, 1970: Studi per una teoria generale del diritto, Torino, Giappichelli. 2003: Teoria da norma jurídica, $2^{a}$ ed., Bauru, Edipro. 1995: O positivismo jurídico - lições de filosofia do Direito, São Paulo: Ícone.

CARVALHO NETO, Pythagoras Lopes de, 2007: A diferenciação do direito e a teoria imperativista da norma jurídica, São Paulo: Dissertação de Mestrado (USP). 
FERRAZJR, Tercio Sampaio, 1997: Direito, retórica e comunicação - subsídios para uma pragmática do discurso jurídico, $2^{a}$ ed., São Paulo, Saraiva.

2000: Teoria da norma jurídica - ensaio de pragmática da comunicação normativa, 4a ed., Rio de Janeiro, Forense.

1994: Introdução ao estudo do direito - técnica, decisão, dominação, 2a ed., São Paulo, Atlas.

HOBBES, Thomas, 2002: Do cidadão, $3^{a}$ ed., São Paulo, Martins Fontes.

2004: Diálogo entre um filósofo e um jurista, São Paulo, Landy.

JHERING, Rudolf von, 2002: A finalidade do Direito, t. I., Campinas, Bookseller.

KELSEN, Hans, 1987: Problemas capitales de la teoría juridica del Estado (desarrollados con base en la doctrina de la proposición jurídica), México, D.F., Editorial Porrúa.

1998: Teoria Geral do Direito e do Estado, 3a ed., São Paulo, Martins Fontes.

2001: A Teoria Pura do Direito e a jurisprudência analítica. In.: O que é justiça?, $3^{a}$ ed., São Paulo, Martins Fontes, pp. 261-83.

1999: Teoria Pura do Direito, 6a ed., São Paulo, Martins Fontes.

LUHMANN, Niklas, 1983: Sociologia do Direito I, Rio de Janeiro, Tempo Brasileiro. 1985: Sociologia do Direito II, Rio de Janeiro, Tempo Brasileiro.

1983: Struttura della società e semantica, Bari, Laterza.

1995: Social systems, Stanford, Stanford University Press

2002: El Derecho de la sociedad, Guadalajara, Iberoamericana.

LUHMANN, Niklas, DE GIORGI, Raffaele, 2003: Teoria della società, $11^{a}$ ed., Milano, Franco Angeli.

NOBLES, Richard, SCHIFF, David, 2006: A sociology of jurisprudence, Oxford, Hart Publishing.

OLIVECRONA, Karl, 1959: El derecho como hecho, Buenos Aires, Roque Depalma.

RAVÀ, Adolfo, 1950: Il diritto come norma tecnica in Diritto e stato nella morale idealistica, Padova, Antonio Milani, pp. 3-120.

VASCONCELOS, Arnaldo, 2002: Teoria da norma jurídica, 5a ed., São Paulo, Malheiros.

WATZLAWICK, Paul, BEAVIN, Janet Helmut, JACKSON, Don, 1998: Pragmática da comunicação humana um estudo dos padrões, patologias e paradoxos da interação, São Paulo, Cultrix.

WIEACKER, Franz, 1993: História do direito privado moderno, 2ª ed., Lisboa, Calouste Gulbekian.

Trabalho enviado em 20 de março de 2016.

Aceito em 09 de maio de 2016. 